ARTICLE

https://doi.org/10.1038/s41467-019-13759-1

\title{
Catalytic processing in ruthenium-based polyoxometalate coacervate protocells
}

Pierangelo Gobbo (1) 1, Liangfei Tian (1) 1,4, B.V.V.S Pavan Kumar (10) 1,4, Samuel Turvey' ${ }^{1}$, Mattia Cattelan (1) ${ }^{2}$, Avinash J. Patil (i) ${ }^{1 \star}$, Mauro Carraro (i] ${ }^{3}$, Marcella Bonchio (i) ${ }^{3 \star} \&$ Stephen Mann ${ }^{1 \star}$

The development of programmable microscale materials with cell-like functions, dynamics and collective behaviour is an important milestone in systems chemistry, soft matter bioengineering and synthetic protobiology. Here, polymer/nucleotide coacervate microdroplets are reconfigured into membrane-bounded polyoxometalate coacervate vesicles ( $P C V s$ ) in the presence of a bio-inspired Ru-based polyoxometalate catalyst to produce synzyme protocells $\left(\mathrm{Ru}_{4} \mathrm{PCV}\right)$ with catalase-like activity. We exploit the synthetic protocells for the implementation of multi-compartmentalized cell-like models capable of collective synzyme-mediated buoyancy, parallel catalytic processing in individual horseradish peroxidase-containing $\mathrm{Ru}_{4} \mathrm{PCV}$, and chemical signalling in distributed or encapsulated multicatalytic protocell communities. Our results highlight a new type of catalytic microcompartment with multi-functional activity and provide a step towards the development of protocell reaction networks.

\footnotetext{
${ }^{1}$ Centre for Organized Matter Chemistry and Centre for Protolife Research, School of Chemistry, University of Bristol, Bristol BS8 1TS, UK. ${ }^{2}$ School of Chemistry, University of Bristol, Bristol BS8 1TS, UK. ${ }^{3}$ ITM-CNR and Dipartimento di Scienze Chimiche, Università di Padova, Via F. Marzolo 1, 35131 Padova, Italy. ${ }^{4}$ These authors contributed equally: Liangfei Tian, B. V. V. S Pavan Kumar. *email: Avinash.Patil@bristol.ac.uk; marcella.bonchio@unipd.it; s.mann@bristol.ac.uk
} 
T he endogenous operation and integration of chemical processes within aqueous filled micro-compartments is providing opportunities for the development of programmable microscale materials with cell-like functions, dynamics and collective behaviors. Membrane-bounded synthetic protocells can be produced in the form of lipid vesicles ${ }^{1-3}$, polymersomes ${ }^{4-7}$, polypeptide capsules ${ }^{8,9}$, dendrimersomes ${ }^{10,11}$, inorganic colloidosomes $^{12-14}$, semi-permeable protein-polymer microcapsules (proteinosomes) ${ }^{15-18}$, and semi-permeable bio-inorganic microcapsules $^{19}$. In addition, coacervate micro-droplets are being exploited as membrane-free protocell models as they selectively sequester key functional components such as biomolecular substrates, proteins, polynucleotides, ribozymes, ribosomes, and chloroplasts $^{20-23}$, and support photochemical reactions, enzyme/ ribozyme cascades and gene expression within their molecularly crowded interior ${ }^{24-28}$. As protocell models, coacervate droplets can be stabilized by enclosure within fatty acid or block copolymer membranes 29,30 , endocytosed within liposomes ${ }^{31}$ and proteinosomes $^{32,33}$, enlisted as predatory protocells ${ }^{34}$, exploited as functional modules in prototissues ${ }^{35}$ and sensing platforms ${ }^{36}$, and reconfigured into fatty acid vesicles 32,37 or membranebounded coacervate vesicles ${ }^{38}$. In the latter case, coacervate droplets prepared from polydiallydimethylammonium chloride (PDDA) and adenosine $5^{\prime}$-triphosphate (ATP) were transformed by electrostatically induced complexation of a polyoxometalate (POM) (sodium phosphotungstate, $\left[\mathrm{PW}_{11} \mathrm{O}_{39}\right]^{7-}$; PTA) with PDDA molecules present at the droplet surface. The concomitant changes in osmotic pressure gave rise to a complex three-tiered microstructure comprising a semi-permeable negatively charged PTA/PDDA outer membrane, a sub-membrane coacervate shell containing guest components, and an internal aqueous lumen ${ }^{38}$. Although the resulting POM coacervate vesicles (PCVs) exhibited no intrinsic chemical reactivity, they could be rendered functional by encapsulation of enzymes within the coacervate submembrane layer.

In this paper, we extend the above approach to the spontaneous preparation of catalytic PCVs by transforming the PDDA/ ATP coacervate droplets in the presence of mixture of PTA and a bio-inspired $\mathrm{Ru}(\mathrm{IV})$-based $\mathrm{POM}$ polyanionic catalyst $\left(\mathrm{Na}_{10}\left[\mathrm{Ru}_{4}(\mu-\mathrm{O})_{4}(\mu-\mathrm{OH})_{2}\left(\mathrm{H}_{2} \mathrm{O}\right)_{4}\left(\gamma-\mathrm{SiW}_{10} \mathrm{O}_{36}\right)_{2}\right] ; \mathrm{Ru}_{4} \mathrm{POM}\right)^{39,40}$ to produce synzyme active protocells $\left(\mathrm{Ru}_{4} \mathrm{PCVs}\right)$ with catalaselike membrane activity. We use $\mathrm{Ru}_{4} \mathrm{POM}$ as an exogenous agent as it is readily synthesized, chemically stable, and forms a strong electrostatic complex with PDDA polycations present at the droplet surface due to its high negative charge. Moreover, the adamantane-like $\mathrm{Ru}$-oxo core of the synzyme comprises four redox active sites connected through $\mu$-oxo and $\mu$-hydroxo bridges, which mimic the natural oxygen evolving photosynthetic center to produce an effective bio-inspired oxygenic catalyst ${ }^{41,42}$. We assess the synzyme activity of the membrane-integrated $\mathrm{Ru}_{4}$ POM structural unit by determining the levels of $\mathrm{O}_{2}$ produced when populations of the $\mathrm{Ru}_{4} \mathrm{PCV}$ are incubated with aqueous $\mathrm{H}_{2} \mathrm{O}_{2}$, and exploit the collective catalase-like activity to design a multi-compartmentalized protocell model capable of endogenously driven buoyancy. By incorporating competitive synzyme and peroxidase reaction pathways within individual protocells we prepare spatially organized networks of $\mathrm{Ru}_{4} \mathrm{PCVs}$ that undergo parallel catalytic processing. Alternatively, we use the same competitive reactions to implement a spatially distributed signaling pathway within a ternary protocell community dispersed in aqueous medium or encapsulated within water-in-oil emulsion droplets. In both cases, the consortium consists of a transmitter population of synzyme-inactive glucose oxidase (GOx)-containing PCVs that endogenously produce a $\mathrm{H}_{2} \mathrm{O}_{2}$ signal and two competitive receiver populations of peroxidase-active or synzyme-active PCVs and $\mathrm{Ru}_{4} \mathrm{PCV}$, respectively. Taken together, our results provide opportunities for the fabrication of new types of catalytic micro-compartments based on membrane-integrated POM clusters and provide a step towards the development of protocell reaction networks.

\section{Results}

Catalytic activity of synzyme protocells. Membrane-free PDDA/ ATP coacervate micro-droplets were structurally and compositionally reconfigured into membrane-bounded coacervate vesicles by addition of an aqueous solution of $\mathrm{Ru}_{4} \mathrm{POM}$ and PTA polyanions (Fig. 1a). Typically, $\mathrm{Ru}_{4} \mathrm{PCV}$ prepared at a PTA: $\mathrm{Ru}_{4} \mathrm{POM}$ molar ratio of 7:1 were intact, non-aggregated, birefringent, and polydisperse (mean diameter, $25 \pm 15 \mu \mathrm{m}$; $30 \mathrm{~s}$ stirring time) (Fig. 1b-d and Supplementary Fig. 1). SEM images confirmed a hollow interior and smooth pliant outer membrane, 500-800 nm in thickness (Fig. 1e and Supplementary Fig. 2), which was consistent with a three-tiered microstructure as described previously for PTA-CVs ${ }^{38}$. $\mathrm{Ru}_{4} \mathrm{PCVs}$ with larger sizes and increased polydispersity were obtained by increasing the extent of coacervate droplet coalescence prior to reconfiguration (Supplementary Fig. 3). $\mathrm{Ru}_{4}$ PCVs were also prepared at lower PTA: $\mathrm{Ru}_{4} \mathrm{POM}$ molar ratios, but were prone to osmotic collapse at $\mathrm{Ru}_{4} \mathrm{POM}$ levels greater than $12 \mathrm{~mol} \%$. Zeta-potential measurements showed a marked decrease in surface potential for the PDDA/ATP droplets from $c a .0 \mathrm{mV}$ to $-35.6 \pm 1.4 \mathrm{mV}$ after formation of the $\mathrm{Ru}_{4}$ PCVs (Supplementary Fig. 4), which was attributed to complexation of excess POM polyanions with PDDA at the droplet/water interface. No change in the surface charge of the $\mathrm{Ru}_{4} \mathrm{PCVs}$ was observed when the $\mathrm{Ru}_{4} \mathrm{POM}$ concentration used in the PCV preparation was varied from 0.12 to $0.48 \mathrm{mmol}$. We attributed this to the large molar excess of POMs required to trigger the coacervate-to-vesicle reconfiguration and the higher negative charge of $\mathrm{Ru}_{4}$ POM compared to PTA. FT-IR, Raman and XPS spectra confirmed the presence of structurally intact PTA and $\mathrm{Ru}_{4} \mathrm{POM}$ species within the PCV membrane (Fig. 1f, g and Supplementary Figs. 5, 6). Quantitative analysis of the XPS data gave a $\mathrm{W}: \mathrm{Ru}$ atomic ratio of $10 \pm 4$, equivalent to an average PTA: $\mathrm{Ru}_{4} \mathrm{POM}$ molar ratio of $1.7: 1$ in the PCV membrane (Supplementary Fig. 6). As the starting ratio was 7:1, the PDDA/ $\mathrm{POM}$ membrane was considerably enriched in $\mathrm{Ru}_{4} \mathrm{POM}$, consistent with the increased electrostatic interactions associated with the higher negative charge.

Given these observations, we tested the in situ synzyme activity of the $\mathrm{Ru}_{4} \mathrm{POM}$ structural unit when integrated into the membrane of the artificial protocells. Specifically, we determined the catalaselike activity by incubating populations of the $\mathrm{Ru}_{4} \mathrm{PCVs}$ with $\mathrm{H}_{2} \mathrm{O}_{2}$, followed by measurement of the $\mathrm{O}_{2}$ produced over a period of 60 min (Fig. $1 \mathrm{~h}$ and Supplementary Fig. 7 ). The $\mathrm{Ru}_{4} \mathrm{PCV}$ s remained intact under the experimental conditions employed (Supplementary Fig. 8). The kinetic plots indicated that the rate of $\mathrm{O}_{2}$ production was proportional to the number of $\mathrm{Ru}_{4} \mathrm{PCVs}$ with a second order rate constant of $43.0 \times 10^{-3} \mathrm{M}^{-1} \mathrm{~s}^{-1}\left(5.90 \times 10^{-8}\right.$ $\left.\mathrm{mg}^{-1} \mathrm{~s}^{-1}\right)$. The rate constant was three orders of magnitude smaller than that determined for homogeneous catalysis in aqueous solutions of $\mathrm{Ru}_{4} \mathrm{POM}\left(36.8 \mathrm{M}^{-1} \mathrm{~s}^{-1}\right)^{43}$, which was attributed to attenuated diffusion of $\mathrm{H}_{2} \mathrm{O}_{2}$ within the POM/polyelectrolyte matrix of the PCV membrane. However, the measured rate constant was comparable to values determined previously for $\mathrm{Ru}_{4} \mathrm{POM}$ in heterogenous catalysis ${ }^{43,44}$, suggesting that the catalytic activity was not unduly hindered within the protocell membrane. In contrast, no catalytic activity was observed when populations of the ruthenium-free PTA-CVs were exposed to $\mathrm{H}_{2} \mathrm{O}_{2}$ under identical reaction conditions.

Having established the synzyme activity of the individual $\mathrm{Ru}_{4}$ PCVs, we exploited their collective catalase-like activity in a 
a
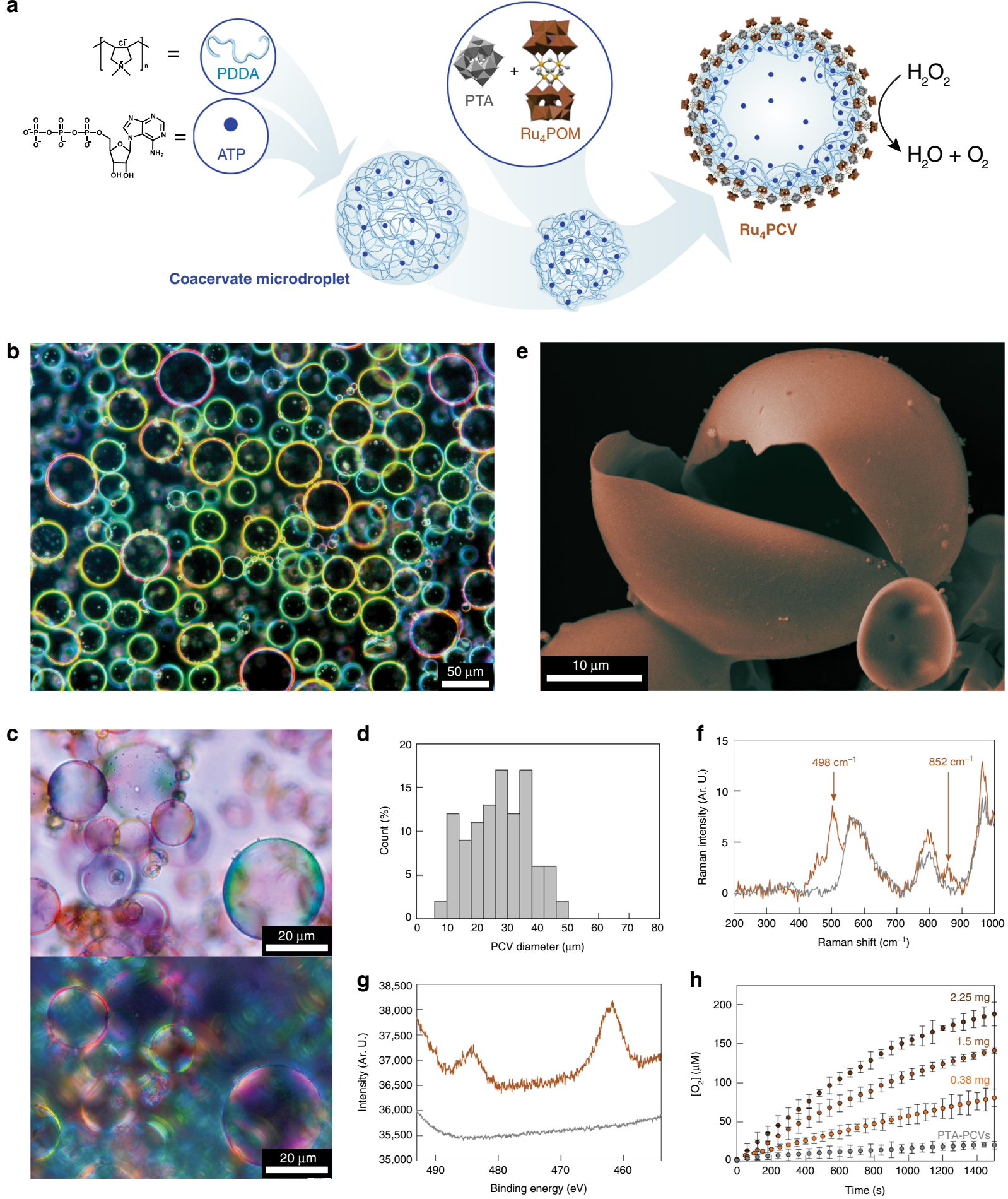

Fig. 1 Self-assembly and catalytic activity of synzyme protocells. a Scheme showing the self-assembly of catalytic $\mathrm{Ru}_{4} \mathrm{PCVs}$. Membrane-free noncatalytic PDDA/ATP coacervate micro-droplets are reconfigured into catalytic membrane-bounded coacervate vesicles by electrostatically induced surface binding of $\mathrm{Ru}_{4} \mathrm{POM}$ and PTA polyanions. Membrane formation is accompanied by changes in osmotic pressure that generate a three-tiered microarchitecture consisting of a Ru${ }_{4}$ POM/PTA/PDDA catalytic membrane, a PDDA/ATP sub-membrane coacervate shell, and an expanded aqueous lumen. b Dark-field microscopy image showing a population of $\mathrm{Ru}_{4} \mathrm{PCV}$ in aqueous solution. $\mathbf{c}$ Bright-field microscopy image of a lyophilized sample of $\mathrm{Ru}_{4} \mathrm{PCVs}$ (top), and corresponding cross-polarized image (bottom) showing birefringence. $\mathbf{d}$ Size distribution for $\mathrm{Ru}_{4} \mathrm{PCVs}$ produced by addition of a Ru $\mathrm{POOM}_{4} \mathrm{PTA}$ mixture (7:1 molar ratio) to coacervate microdroplets after $30 \mathrm{~s}$ of stirring. e SEM image of a lyophilized single Ru $\mathrm{P}_{4} \mathrm{PCV}$ showing hollow interior and smooth outer membrane surface. Images have been artificially colored to mimic the real tinge of the material. $\mathbf{f}$ Raman spectra of lyophilized Ru ${ }_{4} \mathrm{PCVs}$ (light brown) and PTA-CVs (gray) powders. Absorbance bands: $498 \mathrm{~cm}^{-1}$ (Ru-O-Ru str, $\left.\mathrm{Ru}_{4}(\mu-\mathrm{O}){ }_{4}\right) ; 852 \mathrm{~cm}^{-1}$ ( $\mathrm{Si}-\mathrm{O}$ str, $\left[\gamma-\mathrm{SiW}_{10} \mathrm{O}_{36}\right]^{8-}$ ); $575 \mathrm{~cm}^{-1}(\mathrm{O}-\mathrm{P}-\mathrm{O}$ def); 798 $\mathrm{cm}^{-1}$ (W-O-W def); $978 \mathrm{~cm}^{-1}$ (W=O str) $40,52,53$. $\mathbf{g}$ XPS spectra (Ru 3p region) of lyophilized Ru $\mathrm{W}_{4} \mathrm{PCVs}$ (light brown) and PTA-CVs (gray) powders. Photoemission lines for Ru(IV) are observed at $484.5 \mathrm{eV}\left(3 \mathrm{p}_{1 / 2}\right)$ and $462.5 \mathrm{eV}\left(3 \mathrm{p}_{3 / 2}\right)^{54,55}$ in the $\mathrm{Ru}_{4} \mathrm{PCV}$ sample. $\mathbf{h}$ Room temperature kinetic plots of dioxygen evolution against $\mathrm{Ru}_{4} \mathrm{PCV}$ s concentration (mg in PBS buffer $\left(500 \mu \mathrm{L}, 10 \mathrm{mM}, \mathrm{pH} 6.5\right.$, Ar purged)) at $\left[\mathrm{H}_{2} \mathrm{O}_{2}\right]=2.8 \mathrm{M}$ showing protocell-mediated synzyme activity. Absence of activity for the PTA-CVs control samples is also shown. Error bars: standard deviation. 
a

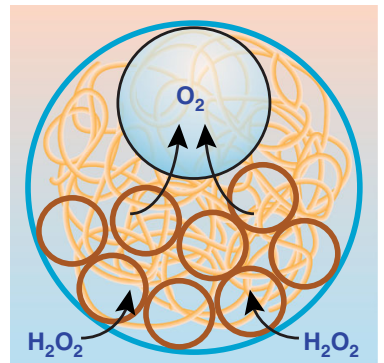

b

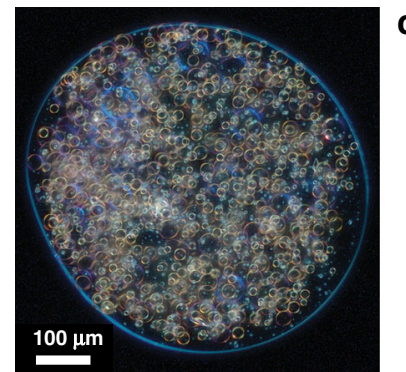

C

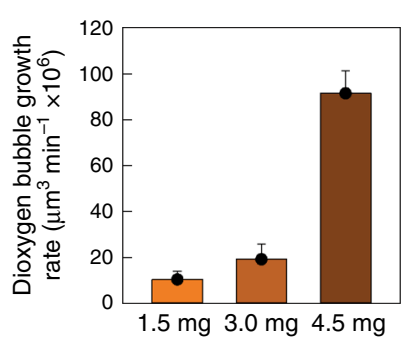

d

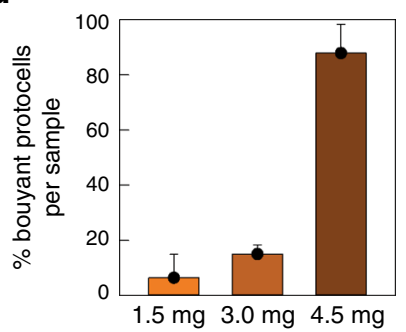

e

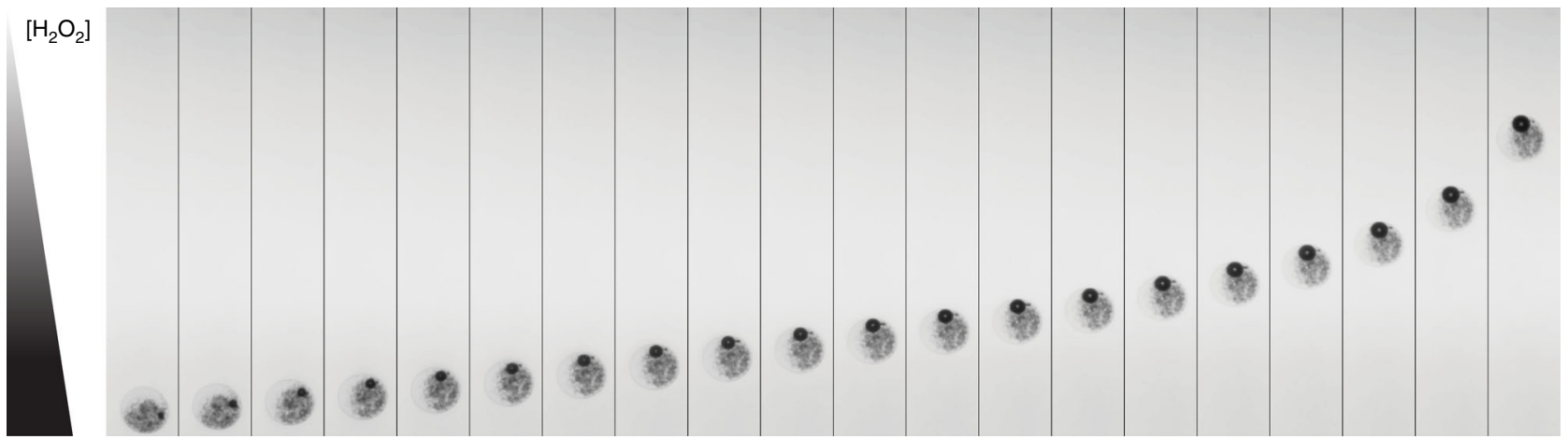

Fig. 2 Collective synzyme activity in multi-compartmentalized protocells. a Scheme illustrating the design and operation of a multi-compartmentalized model protocell exhibiting proto-organelle-mediated buoyancy. The micro-architecture is suspended in water and consists of a semi-permeable aminoclay/ DNA outer membrane (blue circle) that encages a viscous aqueous solution of DNA (orange curved line) containing tens of thousands of Ru ${ }_{4} \mathrm{PCVs}$ (brown circles). Addition of $\mathrm{H}_{2} \mathrm{O}_{2}$ results in proto-organelle-mediated dioxygen production, gas bubble growth and buoyancy-induced vertical movement of the host-guest ensemble. $\mathbf{b}$ Dark field microscopy image recorded in water showing a single aminoclay/DNA protocell containing a dense population of catalytically active $\mathrm{Ru}_{4} \mathrm{PCV}$ s proto-organelles. Typical mean sizes of the host aminoclay/DNA microcapsule and guest $\mathrm{Ru}_{4} \mathrm{PCVs}$ were $530 \pm 13 \mu \mathrm{m}$ and $25 \pm 15 \mu \mathrm{m}$, respectively; estimated free internal volume, $50 \pm 10 \%$; estimated number of encapsulated $\mathrm{Ru}_{4} \mathrm{PCVs}_{\mathrm{s}} 20 \pm 10 \times 10^{3}$. c Plot showing rate of dioxygen bubble formation $\left(\mu \mathrm{m}^{3} \mathrm{~min}^{-1}\right)$ against $\mathrm{Ru}_{4} \mathrm{PCV}$ loading in aminoclay/DNA protocells after exposure to $\mathrm{H}_{2} \mathrm{O}_{2}(4.9 \mathrm{M})$. Loadings are given as mg of $\mathrm{Ru}_{4} \mathrm{PCVs}$ used to prepare the PCV/DNA dispersion. Error bars: standard deviation. d Plot showing the percentage of buoyant multi-compartmentalized protocells against $\mathrm{Ru}_{4} \mathrm{PCV}$ loading after exposure to $\mathrm{H}_{2} \mathrm{O}_{2}(4.9 \mathrm{M})$. Error bars: standard deviation. e Composite image (see Supplementary Movie 1) showing onset and progression of buoyancy for a single $\mathrm{Ru}_{4} \mathrm{PCV}$-containing aminoclay/DNA protocell initially located at the bottom of a water-filled glass cuvette containing a gradient of $\mathrm{H}_{2} \mathrm{O}_{2}$ (higher concentration towards the bottom). The oxygen bubble is observed as a highly refractive black spot inside the protocell. The population of encapsulated $\mathrm{Ru}_{4} \mathrm{PCVs}$ is observed as dark material within the aminoclay/DNA micro-capsules. Frames displayed at intervals of $1.2 \mathrm{~s}$

multi-compartmentalized protocell model prepared by encapsulation of tens of thousands of multiple $\mathrm{Ru}_{4} \mathrm{PCVs}$ within individual semi-permeable aminoclay/DNA microcapsules typically $500 \mu \mathrm{m}$ in size (Fig. 2a). Entrapment of the $\mathrm{Ru}_{4} \mathrm{PCVs}$ within the microcapsules produced a dense population of artificial protoorganelles capable of generating dioxygen in the presence of exogeneous $\mathrm{H}_{2} \mathrm{O}_{2}$ (Fig. $2 \mathrm{~b}$ and Supplementary Fig. 9). Increasing the number of encapsulated $\mathrm{Ru}_{4} \mathrm{PCVs}$ above a critical level resulted in the growth of predominantly single gas bubbles within the multi-compartmentalized protocells (Fig. 2c). As a consequence, an increasing percentage of the nested microarchitectures became buoyant (Fig. 2d), resulting in vertical motility (Fig. 2e and Supplementary Movie 1). Typically, the protocells migrated with an acceleration of $7.5 \pm 0.1 \mu \mathrm{m} \mathrm{s}^{-2}$ when placed at the bottom of a water column containing a gradient of $\mathrm{H}_{2} \mathrm{O}_{2}$ (Supplementary Fig. 10). As expected, multicompartmentalized protocells containing ruthenium-free noncatalytic PTA-CVs guests were not triggered by $\mathrm{H}_{2} \mathrm{O}_{2}$ and remained immobile in the presence of the chemical stimulus (Supplementary Fig. 11 and Supplementary Movie 1).

Parallel catalytic processing in synzyme protocells. Competitive synzyme and enzyme reaction pathways were established within individual $\mathrm{Ru}_{4} \mathrm{PCVs}$ by preparing multi-catalytic protocells capable of parallel reaction processing. For this, horseradish peroxidase (HRP) was sequestered within the coacervate microdroplets prior to structural reconfiguration to produce $\mathrm{Ru}_{4} \mathrm{PCVs}$ that when exposed to aqueous $\mathrm{H}_{2} \mathrm{O}_{2}$ displayed simultaneous membrane-mediated $\mathrm{O}_{2}$ production $\left(\mathrm{Ru}_{4} \mathrm{POM}\right.$ activity) and endogenous peroxidation of membrane-permeable organic substrates (HRP activity). We investigated this system using spatially organized arrays comprising hundreds of immobilized HRPcontaining $\mathrm{Ru}_{4} \mathrm{PCV}$ s produced by acoustic standing wave microdroplet patterning ${ }^{45}$. Initially, a defect-free $2 \mathrm{D}$ array of uniform HRP-containing PDDA/ATP coacervate micro-droplets was generated in situ at the nodes of an acoustic pressure field produced within a custom-made acoustic trapping chamber (Fig. 3a). Fluorescence microscopy images showed a homogenous distribution of sequestered Dylight405-labeled HRP (Fig. 3b), indicating that the potential for endogenous peroxidase activity was uniform throughout the microdroplet community. We then established systematic differences in the catalase-like activity across the array by reconfiguring the spatially organized HRPcontaining coacervate micro-droplets using a unidirectional POM chemical gradient. This was achieved by carefully injecting a $\mathrm{PTA} / \mathrm{Ru}_{4} \mathrm{POM}$ (molar ratio $=7: 1$ ) solution from one side of the trapping device such that the membrane-restructuring agents slowly diffused through the chamber and progressively triggered the coacervate-to-vesicle transformation along an advancing 
reaction-diffusion planar wave front ${ }^{46}$. As a consequence, the uniform community of immobilized coacervate droplets transformed into a ternary population consisting of three spatially separated zones of birefringent $\mathrm{Ru}_{4} \mathrm{PCVs}$ that were morphologically graded along the diffusion direction (Fig. 3c, Supplementary Fig. 12, and Supplementary Movie 2). The differentiated array comprised $\mathrm{Ru}_{4} \mathrm{PCV}$ s that were (i) contracted in volume and spatially discrete (mean diameter, $77 \pm 6 \mu \mathrm{m}$; membrane-tomembrane separation, $38 \pm 7 \mu \mathrm{m}$ ); (ii) slightly expanded in volume (mean diameter, $108 \pm 8 \mu \mathrm{m}$ ) with membrane-membrane contacts; or (iii) highly expanded in volume (mean diameter, $114 \pm 8 \mu \mathrm{m})$ and therefore deformed by membrane-membrane compression forces. Formation of the contracted protocells occurred in regions closest to the point of injection (high PTA and $\mathrm{Ru}_{4} \mathrm{POM}$ levels), suggesting that the collapsed morphology was due to assembly of the semi-permeable membrane under hypertonic (high ionic strength) conditions. In contrast, the two types of swollen $\mathrm{Ru}_{4} \mathrm{PCVs}$ were positioned in regions further away from the injection point where the POM concentrations were decreased (hypotonicity) due to successive binding of PTA/ $\mathrm{Ru}_{4} \mathrm{POM}$ anions to the coacervate droplets during transit of the reaction-diffusion gradient. Under these conditions, the protocells swell due to ATP-mediated osmotically induced ingress of water ${ }^{38}$.

Having established a morphologically graded community of immobilized $\mathrm{HRP}$-containing $\mathrm{Ru}_{4} \mathrm{PCVs}$, we homogeneously exposed the differentiated populations to a mixture of $\mathrm{H}_{2} \mathrm{O}_{2}$ and Amplex Red and monitored the HRP-mediated generation of the red fluorescent product resorufin as a proxy for the degree of competition between the endogenous peroxidase and membrane-mediated catalase-like activities of the multicatalytic protocells. $\mathrm{Ru}_{4} \mathrm{PCVs}$ without $\mathrm{HRP}$ were inactive with regard to Amplex Red peroxidation, indicating minimal levels of crosstalk between the parallel catalytic pathways (Supplementary Fig. 13). Interestingly, although the HRP content was similar for all $\mathrm{Ru}_{4} \mathrm{PCVs}$ in the array, the competition between the enzyme and synzyme activities within individual protocells was spatiotemporally determined. For example, when the transitions between the differentiated protocell populations were engineered to occur within the central observation window of the device chamber (i.e., $15 \mathrm{~mm}$ from the point of injection), a high level of resorufin production was observed in the sub-membrane coacervate layer of the small contracted $\mathrm{Ru}_{4}$ PCVs (Fig. 3d). This was consistent with dominant HRP activity and a reduced level of $\mathrm{Ru}_{4} \mathrm{POM}$ in the membrane of the reconfigured protocells produced in this region of the device. As preferential binding of $\mathrm{Ru}_{4} \mathrm{POM}$ to the coacervate droplets was observed under equilibrium conditions, we attributed the decrease in catalase-like activity to selective depletion of the synzyme as the $\mathrm{PTA} / \mathrm{Ru}_{4} \mathrm{POM}$ chemical gradient advanced towards the observation window. In contrast, the slightly expanded $\mathrm{Ru}_{4} \mathrm{PCV}$ s produced adjacent to the region of HRPdominant contracted $\mathrm{Ru}_{4}$ PCVs showed negligible red fluorescence (Fig. 3d, e), indicating prevailing catalase-like activity and down-regulation of resorufin production in the parallel catalytic pathways. Interestingly, the exchange in chemical processing was observed downstream for thirty or so rows of protocells after which the reactivity reverted to predominant resorufin production in the highly expanded $\mathrm{Ru}_{4} \mathrm{PCVs}$ (Fig. $3 \mathrm{~d}$, e). We attribute these observations to localized changes in membrane composition that originate from fluctuations in the PTA: $\mathrm{Ru}_{4} \mathrm{POM}$ molar ratio as the reaction-diffusion gradient migrates unidirectionally through the protocell array. Initially, the PTA: $\mathrm{Ru}_{4} \mathrm{POM}$ ratio increases above a value of $7: 1$ because $\mathrm{Ru}_{4} \mathrm{POM}$ is preferentially depleted compared with PTA. The resulting higher levels of PTA then lead to more competitive
PTA binding, which in turn lowers the PTA: $\mathrm{Ru}_{4} \mathrm{POM}$ ratio at the advancing diffusion front to generate oscillations in the composition of the PCV membrane. As a consequence, both the contracted and highly expanded morphological forms although spatially separated as populations display dominant HRP activity (high PTA: $\mathrm{Ru}_{4} \mathrm{POM}$ ratios), whilst the slightly expanded protocells that divide these two zones show higher synzyme activity (lower PTA: $\mathrm{Ru}_{4} \mathrm{POM}$ ratios). In contrast, no spatiotemporal catalytic response was observed in arrays of HRP-containing ruthenium-free PTA-CVs exposed to $\mathrm{H}_{2} \mathrm{O}_{2}$ and Amplex Red (Supplementary Fig. 14).

Chemical signaling in multi-catalytic protocell communities. As an alternative approach to implementing synzyme/enzyme parallel processing within individual protocells, we spatially distributed the two functionalities by preparing separate populations of RITC-labeled HRP-containing PTA-CVs and unlabeled $\mathrm{Ru}_{4}$ PCVs. After mixing the two populations, we added a population of FITC-tagged GOx-containing PTA-CVs to produce a ternary community capable of chemical communication and signaling (Fig. $4 \mathrm{a}, \mathrm{b}$ ). In general, addition of glucose in the presence of the HRP-substrate $o$-phenylenediamine (o-PD) produced an endogenous $\mathrm{H}_{2} \mathrm{O}_{2}$ signal that was diffusively transmitted from the GOx-containing PTA-CVs to the two types of receiver protocells, which catalytically processed the signal in parallel. To monitor the peroxidation reaction against catalase-like activity we used fluorescence microscopy to detect the production and trafficking of the green fluorescent peroxidation product 2,3-diaminophenazine (2,3-DAP) within and between the different individual protocells (Fig. 4c). Oxygen production specifically within the $\mathrm{Ru}_{4} \mathrm{PCVs}$ was not monitored due to experimental constraints. As expected, production of 2,3-DAP occurred specifically within the HRP-containing PTA-CVs, where it was initially sequestered to give an intense green fluorescence within the membrane and sub-membrane layer of the PCVs (Supplementary Movie 3). This was followed by slow efflux of the fluorescent product and subsequent sequestration of 2,3-DAP by both the GOx-containing PTA-CVs and $\mathrm{Ru}_{4} \mathrm{PCVs}$ (typically within $20 \mathrm{~min}$ ). Minimal levels of green fluorescence were recorded in the aqueous background (Fig. 4c), indicating that $c a$. $98 \%$ of the peroxidation product was retained within the protocell community. Increasing the number of $\mathrm{Ru}_{4} \mathrm{PCVs}$ included in ternary populations prepared at a constant GOx-PTA-CV:HRPPTA-CV ratio (1:1 wt/wt) and fixed substrate concentrations resulted in a corresponding decrease in 2,3-DAP production due to enhanced synzyme activity (Fig. $4 \mathrm{~d}$ and Supplementary Fig. 15). In general, $\mathrm{Ru}_{4} \mathrm{PCV}$ : PTA-CV number ratios greater than 3.0 were required to attenuate the peroxidase activity, indicating that parallel processing of the endogenous $\mathrm{H}_{2} \mathrm{O}_{2}$ signal was less pronounced than compared with integration of the catalytic pathways into individual protocells (Fig. 4d).

Finally, we adopted the above model system as a step towards a nested synthetic protocell capable of operating an endogenous sequence of multi-catalytic inter-proto-organelle pathways. For this, we incarcerated the above ternary population along with glucose and $o$-PD within individual water-in-oil emulsion droplets enclosed within a protein-polymer nanoconjugate membrane (Fig. 4e, f and Supplementary Fig. 16) ${ }^{15}$ Production of 2,3-DAP in the compartmentalized community was monitored by optical and fluorescence microscopy (Fig. 4g and Supplementary Movie 4). The images revealed a sequence of spatiotemporal responses that were similar to that observed in communities of the spatially distributed protocells except that 2,3-DAP was progressively removed from the reaction environment by solubilization in the oil phase. 
a

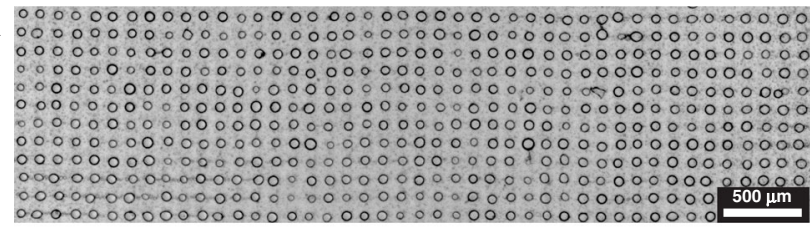

b
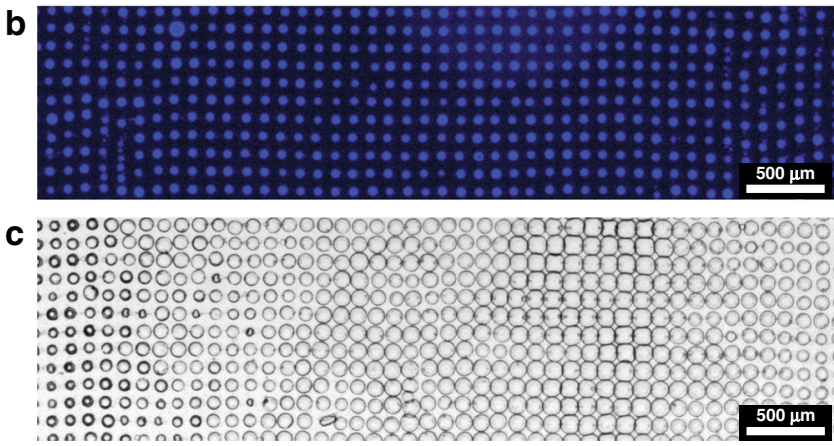

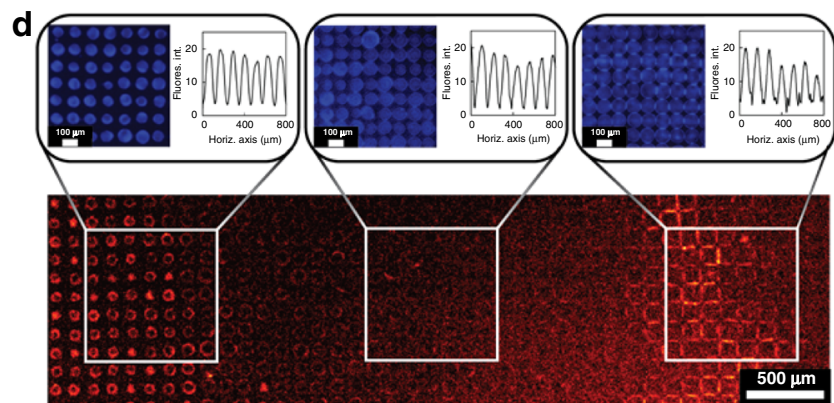

e

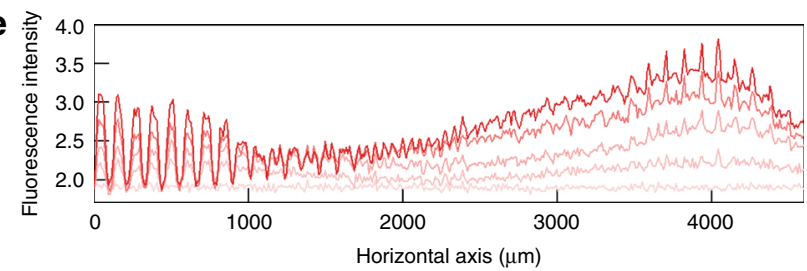

Fig. 3 Parallel catalytic processing in synzyme protocells. a Brightfield microscopy image showing an acoustically trapped 2D array of immobilized HRPcontaining PDDA/ATP coacervate microdroplets. The field of view is $5.0 \times 1.5 \mathrm{~mm}$. b Corresponding fluorescence microscopy image showing the homogenous distribution of sequestered Dylight405-labeled HRP (blue fluorescence) within individual coacervate droplets throughout the acoustically patterned array. c Brightfield microscopy image showing reconfiguration of a uniform population of HRP-containing coacervate droplets into a spatially separated trimodal community after exposure to a unidirectional PTA/Ru $u_{4} \mathrm{POM}$ chemical gradient. The PTA $/ \mathrm{Ru}_{4} \mathrm{POM}$ mixture $\left(7.5 \mu \mathrm{L}, \mathrm{PTA}: \mathrm{Ru}_{4} \mathrm{POM}=7: 1\right.$ $\mathrm{mol} / \mathrm{mol} ;[\mathrm{PTA}]=17.6 \mathrm{mM} ;\left[\mathrm{Ru}_{4} \mathrm{POM}\right]=2.4 \mathrm{mM} ; \mathrm{pH} 6.5$ ) was injected to the left of the image at a distance of $15 \mathrm{~mm}$ from the observation window $\left(5.0 \times 1.5 \mathrm{~mm}\right.$ ). Distinct zones of non-contact small-sized $\mathrm{Ru}_{4} \mathrm{PCVs}$ (left side), medium-sized $\mathrm{Ru}_{4} \mathrm{PCVs}$ with membrane-membrane contacts (center), and highly expanded $\mathrm{Ru}_{4} \mathrm{PCVs}$ showing compression-induced deformation (center right) are observed (see Supplementary Movie 2). d Fluorescence microscopy images of an array of HRP-containing $\mathrm{Ru}_{4} \mathrm{PCVs} 16$ min after homogeneous addition of $\mathrm{H}_{2} \mathrm{O}_{2}$ and Amplex Red (final concentrations 40 and $10 \mu \mathrm{M}$, respectively). The bottom image shows zones (left and right sides) of red fluorescence arising from protocells operating with a dominant HRPmediated pathway giving rise to a resorufin output. The central region shows only background levels of red fluorescence due to prevailing synzyme activity and competitive decomposition of $\mathrm{H}_{2} \mathrm{O}_{2}$ to $\mathrm{O}_{2}$ and water. A homogenous distribution of coacervate-sequestered Dylight405-labeled HRP (blue

fluorescence) is observed throughout the array (top images). Selected regions are delineated by the white squares and top images show blue fluorescence images and corresponding fluorescence intensity line profiles. e Time-dependent averaged resorufin fluorescence line intensity profiles recorded across the array shown in $\mathbf{d}$. Increasing color saturation indicates increased elapsed time. Time intervals = 0, 4, 8, 12, and 16 min.

\section{Discussion}

In summary, membrane-free molecularly crowded PDDA/ATP coacervate microdroplets are spontaneously reconfigured into catalytic membrane-bounded coacervate vesicles in the presence of $\mathrm{Ru}_{4} \mathrm{POM}$ and PTA polyanionic clusters. Catalytic dismutation of $\mathrm{H}_{2} \mathrm{O}_{2}$ at the tetra- $\mathrm{Ru}(\mathrm{IV})$ synzyme core is associated specifically with the membrane of the coacervate vesicle and can be used collectively within large multi-compartmentalized synthetic protocells to internally generate sufficient amounts of oxygen that give rise to catalytically powered gas-induced flotation. Incorporation of membrane-mediated synzyme and endogenous peroxidase reaction pathways within individual protocells provides a step to competitive parallel catalytic processing, which can be expressed collectively in graded communities of spatially organized $\mathrm{Ru}_{4} \mathrm{PCV}$. The two catalytic pathways can also be spatially separated by incorporation into individual populations of peroxidase-active or synzyme-active PCVs and $\mathrm{Ru}_{4} \mathrm{PCVs}$, respectively. When used in conjunction with a $\mathrm{H}_{2} \mathrm{O}_{2}$ signaling population of GOx-active PCVs, this gives rise to a distributed transmitter-receiver network in a ternary protocell community, which can be encapsulated and subsequently exploited to implement synzyme/enzyme parallel processing within a nested protocell model.

Taken together, our results open up the possibility of using inorganic POM catalysts for the spontaneous self-assembly of membrane-bounded micro-compartments with bioinspired properties. As the synzyme protocells are assembled via a singlestep aqueous-based process, the methodology could offer potential advantages in terms of simplification and scale-up compared with Pickering emulsification (colloidosomes, proteinosomes, and emulsion droplets) and microfluidic processing (lipid vesicles, hydrogel particles). Moreover, the ability to spontaneously generate hierarchical $\mathrm{Ru}_{4} \mathrm{PCVs}$ in water could offer numerous functional advantages over vesicles, polymersomes and hydrogel particles, which generally exhibit homogeneous structures and compositions. For example, vis-à-vis the significant potential of tenable POM structures for bio-inspired catalysis ${ }^{47-50}$, the ability to synthesize such compounds in relatively large quantities, and the resilience of POMs under adverse reaction conditions compared to biomolecular catalysts, it seems feasible that communities of synzyme protocells could provide a step towards synthetic metabolic networks based on light-activated stimuli ${ }^{47}$. More generally, the development of microscale catalytic materials with programmable cell-like functions, dynamics and interactivity could provide new opportunities in microscale systems chemistry, soft matter bioengineering, and synthetic protobiology.

\section{Methods}

Synthesis of $\mathbf{R u}_{4} \mathbf{P O M} . \mathrm{Na}_{10}\left[\mathrm{Ru}_{4}(\mu-\mathrm{O})_{4}(\mu-\mathrm{OH})_{2}\left(\mathrm{H}_{2} \mathrm{O}\right)_{4}\left(\gamma-\mathrm{SiW}_{10} \mathrm{O}_{36}\right)_{2}\right]$ $\left(\mathrm{Ru}_{4} \mathrm{POM}\right)$ was synthesized according to the procedure established by Sartorel and co-workers ${ }^{40}$. In brief, in a typical synthesis, $188 \mathrm{mg}(0.72 \mathrm{mmol})$ of ruthenium chloride trihydrate were dissolved in $30 \mathrm{~mL}$ of deionized water. To this solution, $1 \mathrm{~g}$ $(0.336 \mathrm{mmol})$ of $\mathrm{K}_{8}\left[\gamma-\mathrm{SiW}_{10} \mathrm{O}_{36}\right] \cdot 12 \mathrm{H}_{2} \mathrm{O}$ was directly added. The resulting dark brown solution was kept at $70^{\circ} \mathrm{C}$ for $1 \mathrm{~h}$. After the thermal treatment, the $\mathrm{pH}$ dropped to 1.8, and the solution was filtered. An excess of $\mathrm{CsCl}(4.4 \mathrm{~g}, 26 \mathrm{mmol})$ was then added to precipitate the product as the corresponding cesium salt, which was then washed three times with $2-3 \mathrm{~mL}$ of cold water. Nine hundred and eighty milligram of crude $\mathrm{Ru}_{4} \mathrm{POM}$ cesium salt were obtained in $85 \%$ yield. The cesium salt was then dissolved in $100 \mathrm{~mL}$ of water, and the corresponding sodium salt was obtained by passing it through a Na${ }^{+}$exchange resin (Amberlite 


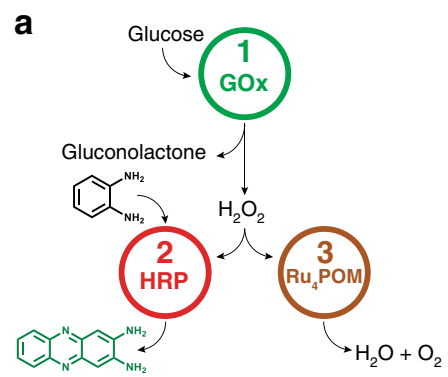

e

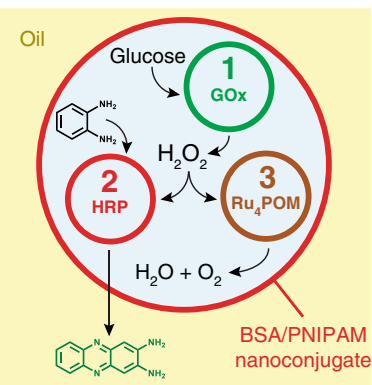

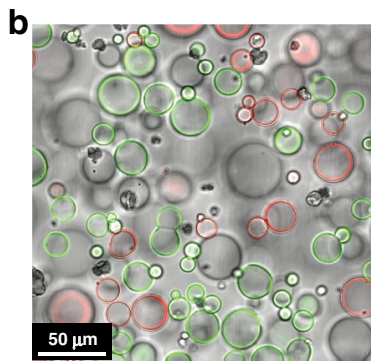

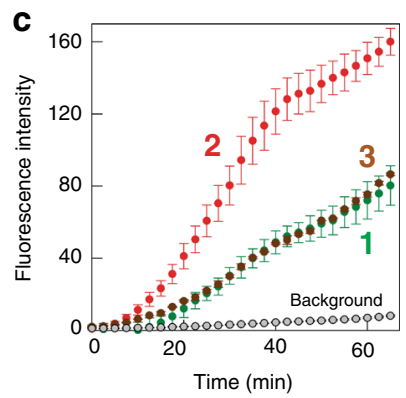

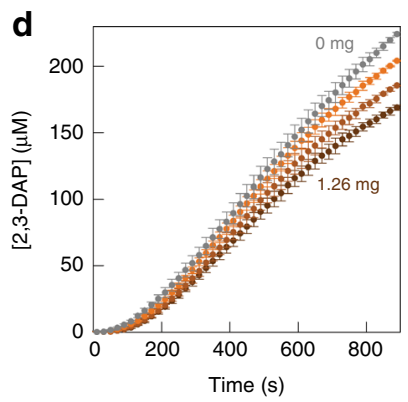
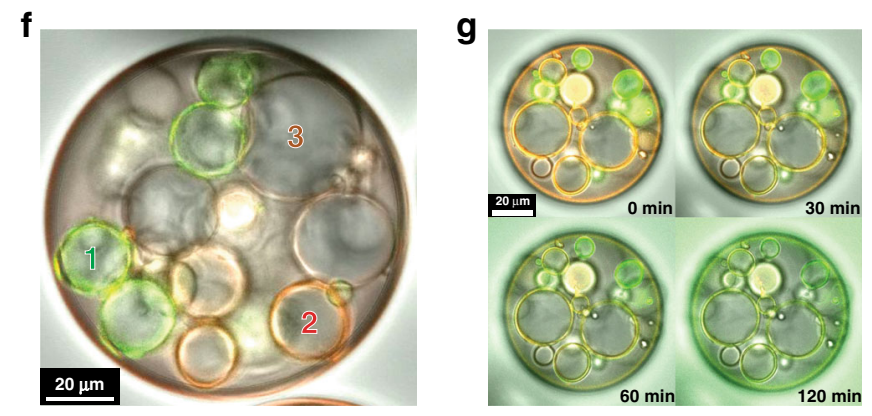

Fig. 4 Chemical signaling in distributed and compartmentalized multi-catalytic protocell communities. a Scheme showing a ternary population comprising a single transmitter protocell (FITC-tagged GOx-containing PTA-CVs; green circle, 1) and two competitive receiver protocells (RITC-tagged HRP-containing PTA-CVs (red circle, 2) and untagged $\mathrm{Ru}_{4} \mathrm{PCVs}$ (brown circle, 3). A glucose input generates a protocell-mediated $\mathrm{H}_{2} \mathrm{O}_{2}$ signal that in the presence of o-PD activates peroxidase and synzyme activities simultaneously to give two competitive outputs (green fluorescent 2,3-DAP or $\mathrm{O}_{2}$, respectively). b Superimposed brightfield and fluorescence confocal microscopy image showing aqueous mixture of 1 (green fluorescence), 2 (red fluorescence) and 3 (no fluorescence) in PBS buffer (0.01 M, pH 6.5) prior to addition of glucose. Relative numbers of protocells was 1:1:1. c Plots of timedependent changes in green fluorescence intensity associated with 2,3-DAP production and transfer in different individual protocells shown in $\mathbf{b}$ after addition of glucose (final concentration, $50 \mathrm{mM}$ ) (see Supplementary Movie 3). On receipt of the $\mathrm{H}_{2} \mathrm{O}_{2}$ signal, production of 2,3-DAP occurs in 2 (red data points) followed by equal rates of diffusive transfer and capture of 2,3-DAP by protocells 1 (green) and 3 (brown). Minimal background green fluorescence is observed (gray plot). Error bars: standard deviation. $\mathbf{d}$ Graph showing the time-dependent generation of 2,3-DAP as determined by plate reader measurements on dispersed ternary communities comprising constant numbers of $1(0.08 \mathrm{mg})$ and $2(0.08 \mathrm{mg})$, and increasing numbers of 3 (Ru $\mathrm{R}_{4} \mathrm{PCV}$; 0 (gray plot), 0.23 (light brown), 0.63 (brown), and $1.26 \mathrm{mg}$ (dark brown). Reactions were initiated by addition of glucose and o-PD at final concentrations of $50 \mathrm{mM}$ and $1 \mathrm{mM}$, respectively. Increased numbers of $\mathrm{Ru}_{4} \mathrm{PCVs}$ progressively decrease the production of 2,3-DAP. Error bars: standard deviation.

e Scheme showing compartmentalization of a ternary proto-organelle population capable of operating a parallel signaling cascade within individual waterin-oil emulsion droplet. The emulsion droplets are stabilized by a self-assembled monolayer membrane of a protein-polymer (BSA/PNIPAM)

nanoconjugate and serve as a host for the synthetic proto-organelles. $\mathbf{f}$ Superimposed brightfield and fluorescence confocal microscopy image of a single water-in-oil emulsion droplet containing an aqueous mixture of protocells 1 (green fluorescence), 2 (red fluorescence) and 3 (no fluorescence). $\mathbf{g}$ As shown in $\mathbf{f}$ but at various reaction times $(t=0,30,60$, and $120 \mathrm{~min})$ and in the presence of glucose and o-PD in the water phase ( 50 and $1 \mathrm{mM}$, respectively). The video time-shots show a progressive increase in green fluorescence within protocells 1, 2, and 3 as well as in the oil phase due to 2,3-DAP production in 2 (see Supplementary Movie 4).

IR120 sodium form). Eight hundred and fifty milligram of crude $\mathrm{Ru}_{4} \mathrm{POM}$ sodium salt were obtained. The crude sodium salt was then purified by size-exclusion chromatography (Sephadex G-50 column, Sigma-Aldrich). The solvent was finally removed to give $700 \mathrm{mg}$ of purified $\mathrm{Ru}_{4} \mathrm{POM}$ sodium salt in $70 \%$ yield (based on initial tungsten).

Preparation of $\mathbf{R u}_{\mathbf{4}}$ PCVs. In sequence, PDDA ( $10 \mathrm{mM}, 500 \mu \mathrm{L}, \mathrm{pH}$ 6.5) and ATP stock solutions $(10 \mathrm{mM}, 500 \mu \mathrm{L}, \mathrm{pH} 6.5)$ were added to a $1.75 \mathrm{~mL}$ vial and stirred $\left(1700 \mathrm{rpm}, 30 \mathrm{~s}\right.$.) to form PDDA/ATP coacervate microdroplets $\left(\mathrm{PDDA}_{\text {monomer: }}\right.$ ATP molar ratio $=1: 1)$. To this stirring solution a freshly prepared mixture of PTA and $\mathrm{Ru}_{4} \mathrm{POM}$ solution $(100 \mu \mathrm{L})$, prepared by mixing a stock solution of PTA $(80 \mu \mathrm{L}, 22 \mathrm{mM}, \mathrm{pH} 6.5)$ and a stock solution of $\mathrm{Ru}_{4} \mathrm{POM}(20 \mu \mathrm{L}, 12 \mathrm{mM}, \mathrm{pH} 6.5)$, was quickly injected. The PCVs dispersion was stirred for $30 \mathrm{~s}$ at $1700 \mathrm{rpm}$ and then transferred into an Eppendorf tube. The PCVs were let to sediment for $30 \mathrm{~min}$, subsequently the supernatant was carefully removed and replaced with $500 \mu \mathrm{L}$ of PBS buffer $0.01 \mathrm{M} \mathrm{pH}$ 6.5. This washing procedure was repeated three times to finally give a batch of $\mathrm{Ru}_{4} \mathrm{PCVs}$ dispersed in $500 \mu \mathrm{L}$ of PBS buffer $(10 \mathrm{mM}$, $\mathrm{pH}$ 6.5). Each batch of $\mathrm{Ru}_{4} \mathrm{PCVs}$ prepared by this methodology contained $1.5 \pm$ $0.5 \mathrm{mg}$ of PCVs as determined by lyophilizing and weighing the samples prepared as described above but washed with MilliQ water instead of PBS buffer. Alternatively, gentle centrifugation $(2 \mathrm{~min}, 94 \times g)$ was used to speed up the washing process; however, small PCV aggregates were often produced by this method.

Before each experiment, the $\mathrm{Ru}_{4} \mathrm{PCV}$ samples were resuspended by stirring on a vortex to obtain a homogenous PCV dispersion.
Preparation of PTA-CVs. PTA-CVs were produced using the procedure described above, with the exception that only the PTA stock solution $(100 \mu \mathrm{L}, 22 \mathrm{mM}, \mathrm{pH}$ 6.5) was added to the stirred coacervate phase instead of the $\mathrm{Ru}_{4} \mathrm{POM} / \mathrm{PTA}$ mixture.

Synthesis of aminoclay. Aminopropyl-functionalized magnesium phyllosilicate (AMP; amino-clay) was prepared according to the procedure established by Burkett and co-workers ${ }^{51}$. In a typical synthesis, AMP clay was prepared by dropwise addition of 3-aminopropyltriethoxysilane $(1.3 \mathrm{~mL}, 5.85 \mathrm{mmol})$ to an ethanol solution of magnesium chloride $(0.84 \mathrm{~g}, 3.62 \mathrm{mmol})$. The aminoclay precipitated within $5 \mathrm{~min}$ as white powder, which was stirred overnight, before being collected by centrifugation, washed with ethanol for three times and dried at $40^{\circ} \mathrm{C}$.

$\mathrm{Ru}_{4} \mathrm{PCV}$-containing aminoclay/DNA synthetic protocells. First, three unwashed samples with different amount of $\mathrm{Ru}_{4} \mathrm{PCVs}(1.5,3.0$, and $4.5 \mathrm{mg})$ were prepared according to the procedure described above and allowed to sediment for $30 \mathrm{~min}$. In general, the supernatant was then removed, and the PCV sediment was mixed with $200 \mu \mathrm{L}$ of aqueous DNA $\left(20 \mathrm{mg} \mathrm{mL}^{-1}\right)$. The resulting homogeneous stable dispersion was then diluted to $500 \mu \mathrm{L}$ with RNA-free water and transferred to a $1 \mathrm{~mL}$ plastic syringe equipped with a hypodermic needle (25 gauge) and a nozzle. To generate $\mathrm{Ru}_{4} \mathrm{PCV}$-containing aminoclay/DNA synthetic protocells, the homogeneous DNA/PCV dispersion was extruded at a flow rates of $10 \mu \mathrm{L} \mathrm{min}{ }^{-1}$. A flow of air $(2 \mathrm{~L} \mathrm{~min}-1)$ was directed through a Tefzel tube $(0.50 \mathrm{~mm}$ internal diameter, VICI, JR-T-082-M3) into the nozzle to generate a coaxial air jet around the hypodermic needle to shear the extruded DNA/PCV dispersion into micro- 
droplets into a freshly exfoliated aminoclay solution $\left(5 \mathrm{mg} \mathrm{mL}^{-1}\right)$ placed below the nozzle. The microcapsules were washed with dilute dispersion of the aminoclay solution $\left(0.5 \mathrm{mg} \mathrm{mL}^{-1}\right)$ and stored in the same solution.

PTA-CV-containing aminoclay/DNA microcapsules for control experiments were prepared following the same procedure but using an unwashed 3-batchconcentrated PTA-CV dispersion in place of $\mathrm{Ru}_{4} \mathrm{PCVs}$.

Preparation of 2D PCV arrays. The PDDA/ATP coacervate micro-droplet array was prepared in a custom-built acoustic trapping device with a square arrangement of four piezoelectric transducers (Noliac, NCE 51, L15 $\times$ W2 $\times$ T1 mm). The opposing transducer pairs were wired in parallel, driven by two signal generators (Agilent 33220a-001), and each connected to an oscilloscope (Agilent DSOX2014A). A PEGylated glass coverslip was attached with adhesive to the bottom of the device. Neutrally charged PDDA/ATP coacervate micro-droplets were prepared in situ by adding an aqueous solution of ATP $(100 \mu \mathrm{L}, 50 \mathrm{mM}, \mathrm{pH}$ 6.5) to an aqueous solution of PDDA ( $1 \mathrm{~mL}, 5 \mathrm{mM}$ monomer, $100-200 \mathrm{kDa}, \mathrm{pH}$ 6.5) in the presence of the two orthogonal acoustic standing waves generated from opposing transducer pairs operating at $6.76 / 6.78 \mathrm{MHz}(10 \mathrm{~V})$. The mixtures were stirred to ensure homogeneous formation of the coacervate droplets in the square chamber. Continuous coalescence of the trapped coacervate droplets at the pressure nodes $(30 \mathrm{~min})$, produced a microdroplet array. The supernatant in the acoustic chamber was carefully removed and exchanged with Milli-Q water for three times under the same acoustic force field. Then, the acoustic field was switched off, and a mixture of PTA and $\mathrm{Ru}_{4} \mathrm{POM}(7.5 \mu \mathrm{L}$, $\left.\mathrm{PTA} / \mathrm{Ru}_{4} \mathrm{POM} 7: 1 \mathrm{~mol} / \mathrm{mol} ;[\mathrm{PTA}]=17.6 \mathrm{mM} ;\left[\mathrm{Ru}_{4} \mathrm{POM}\right]=2.4 \mathrm{mM} ; \mathrm{pH} 6.5\right)$ was added to the acoustic trapping chamber from one side of the device. Optical microscope images were recorded at the center of the trapping chamber with an observation window of $5 \times 1.5 \mathrm{~mm}$

For the control experiments we adopted the same procedure described above, but instead of a mixture of PTA and $\mathrm{Ru}_{4} \mathrm{POM}$ we added a solution of PTA $(7.5 \mu \mathrm{L}$, $20 \mathrm{mM}$ ) to the acoustic trapping chamber.

Preparation of FITC-tagged GOx and RITC-tagged HRP. Enzymes GOx or HRP $(20 \mathrm{mg})$ were dissolved in $\mathrm{Na}_{2} \mathrm{CO}_{3}$ buffer $(7 \mathrm{~mL}, 0.1 \mathrm{M}, \mathrm{pH}$ 8.5). Solutions of RITC or FITC in DMSO $\left(1 \mathrm{mg} \mathrm{mL}^{-1}\right)$ were freshly prepared. The RITC solution $(200 \mu \mathrm{L})$ was added dropwise to the stirring HRP solution, and the FITC solution $(200 \mu \mathrm{L})$ was added dropwise to the stirring GOx solution. The solutions were stirred overnight at $4{ }^{\circ} \mathrm{C}$, purified by dialysis $(8 \mathrm{~h}, 2.5 \mathrm{~L}$ water replaced three times), and lyophilized.

The degree of labeling (DOL) of FITC-tagged GOx and RITC-tagged HRP were calculated using UV-Vis spectroscopy [FITC $\varepsilon(495 \mathrm{~nm})=84,000 \mathrm{~L} \mathrm{~mol}^{-1} \mathrm{~cm}^{-1}$; RITC $\varepsilon(559 \mathrm{~nm})=62,100 \mathrm{~L} \mathrm{~mol}^{-1} \mathrm{~cm}^{-1}$; GOx $\varepsilon(280 \mathrm{~nm})=3,006,000 \mathrm{~L} \mathrm{~mol}^{-1} \mathrm{~cm}^{-1}$, HRP $\left.\varepsilon(403 \mathrm{~nm})=102,000 \mathrm{~L} \mathrm{~mol}^{-1} \mathrm{~cm}^{-1}\right]$. DOL values were determined as 58 for FITC-GOx and 3 for RITC-HRP.

FITC-tagged GOx-containing or RITC-tagged HRP-containing PTA-CVs. FITCtagged GOx-containing or RITC-tagged HRP-containing PCVs were prepared following our standard procedure for PTA-CVs reported in section 1.3, with the exception that the relevant solution of either FITC-tagged GOx $\left(25 \mu \mathrm{L}, 4 \mathrm{mg} \mathrm{mL}^{-1}\right)$ or RITC-tagged HRP $\left(25 \mu \mathrm{L}, 2 \mathrm{mg} \mathrm{mL}^{-1}\right)$ was stirred with PDDA $(500 \mu \mathrm{L}, 10 \mathrm{mM})$ before the addition of ATP.

To determine the partition coefficient $(K)$ of FITC-tagged GOx or RITC-tagged HRP between PCV and bulk solution, the washing procedure was not performed, and images of the fluorescent PCV samples were acquired by fluorescence confocal microscopy and analysed with ImageJ software. The partition coefficient was experimentally determined as the ratio between the fluorescence intensity of the PCV PDDA/ATP submembrane and the fluorescence intensity of the bulk solution, using the following equation:

$$
K=\frac{F_{\mathrm{PCV}}}{F_{\text {bulk }}} \equiv \frac{C_{\mathrm{PCV}}}{C_{\text {bulk }}},
$$

where $F_{\mathrm{PCV}}$ is the fluorescence intensity of the PCV PDDA/ATP submembrane, $F_{\text {bulk }}$ is the fluorescence intensity of the bulk solution, $C_{\mathrm{PCV}}$ is the concentration of enzyme in the PCV PDDA/ATP submembrane, $C_{\text {bulk }}$ is the concentration of enzyme in the bulk solution.

The total concentration of enzyme in the unwashed PCV sample $\left(C_{\mathrm{Tot}} ; C_{\mathrm{Tot}}\right.$ of $\mathrm{GOx}=88.9 \mu \mathrm{g} \mathrm{mL}^{-1} ; C_{\text {Tot }}$ of $\mathrm{HRP}=44.4 \mu \mathrm{g} \mathrm{mL}^{-1}$ ) can be written as:

$$
C_{\mathrm{Tot}}=C_{\mathrm{PCV}}+C_{\mathrm{bulk}}
$$

This gives two unknowns and two equations, which can be solved for $C_{\mathrm{PCV}}$ and $C_{\text {bulk, giving: }}$

$$
\begin{gathered}
C_{\mathrm{PCV}}=\frac{K C_{\mathrm{Tot}}}{1+K} \\
C_{\text {bulk }}=\frac{C_{\mathrm{Tot}}}{1+K}
\end{gathered}
$$

$C_{\mathrm{PCV}}$ for the FITC-tagged GOx-containing PCVs was found to be $87.0 \mu \mathrm{g} \mathrm{mL}-1$ $C_{\mathrm{PCV}}$ for the FITC-tagged GOx-containing PCVs was found to be $42.7 \mu \mathrm{g} \mathrm{mL}-1$.

To verify that the enzymes were effectively sequestered inside the $\mathrm{Ru}_{4} \mathrm{PCVs}$ and were not leaking out during the washing procedure, we put $20 \mu \mathrm{L}$ of unwashed enzyme-filled PTACV dispersion on a microscope cover slip, further diluted it 2, 5 , and 10 times, and acquired fluorescence confocal microscopy images. Using Image and the method reported above we then determined $K$, which was found to increase linearly with the dilution factor $(D)$ indicating that the enzymes were effectively retained within the PCV membrane.

Synthesis of RITC-labeled BSA/PNIPAM nanoconjugate. The RITC-labeled BSA/PNIPAM nanoconjugate was prepared according to a previously established procedure ${ }^{15}$.

\section{Data availability}

The authors declare that all relevant data supporting the finding of this study are available within the paper and its Supplementary Information files. Additional data are available from the corresponding author upon request.

Received: 24 July 2019; Accepted: 19 November 2019; Published online: 03 January 2020

\section{References}

1. Altamura, E. et al. Highly oriented photosynthetic reaction centers generate a proton gradient in synthetic protocells. Proc. Natl Acad. Sci. USA 114, 3837-3842 (2017)

2. Adamala, K. P., Martin-Alarcon, D. A., Guthrie-Honea, K. R. \& Boyden, E. S. Engineering genetic circuit interactions within and between synthetic minimal cells. Nat. Chem. 9, 431-439 (2017).

3. Noireaux, V., Bar-Ziv, R., Godefroy, J., Salman, H. \& Libchaber, A. Toward an artificial cell based on gene expression in vesicles. Phys. Biol. 2, P1-P8 (2005)

4. Peters, R., Louzao, I. \& van Hest, J. C. M. From polymeric nanoreactors to artificial organelles. Chem. Sci. 3, 335-342 (2012).

5. Kubilis, A., Abdulkarim, A., Eissa, A. M. \& Cameron, N. R. Giant polymersome protocells dock with virus particle mimics via multivalent glycan-lectin interactions. Sci. Rep. 6, 32414 (2016).

6. Peyret, A. et al. Polymersome popping by light-induced osmotic shock under temporal, spatial, and spectral control. Angew. Chem. Int. Ed. 56, 1566-1570 (2017).

7. Marguet, M., Bonduelle, C. \& Lecommandoux, S. Multicompartmentalized polymeric systems: towards biomimetic cellular structure and function. Chem. Soc. Rev. 42, 512-529 (2013).

8. Bellomo, E. G., Wyrsta, M. D., Pakstis, L., Pochan, D. J. \& Deming, T. J. Stimuli-responsive polypeptide vesicles by conformation-specific assembly. Nat. Mater. 3, 244-248 (2004).

9. Holowka, E. P., Sun, V. Z., Kamei, D. T. \& Deming, T. J. Polyarginine segments in block copolypeptides drive both vesicular assembly and intracellular delivery. Nat. Mater. 6, 52-57 (2007).

10. Xiao, Q. et al. Bioactive cell-like hybrids coassembled from (glyco) dendrimersomes with bacterial membranes. Proc. Natl Acad. Sci. USA 113, E1134-E1141 (2016).

11. Percec, V. et al. Self-assembly of Janus Dendrimers into uniform Dendrimersomes and other complex architectures. Science 328, 1009-1014 (2010).

12. Li, M., Harbron, R. L., Weaver, J. V. M., Binks, B. P. \& Mann, S. Electrostatically gated membrane permeability in inorganic protocells. Nat. Chem. 5, 529-536 (2013).

13. Rodriguez-Arco, L., Li, M. \& Mann, S. Phagocytosis-inspired behaviour in synthetic protocell communities of compartmentalized colloidal objects. Nat. Mater. 16, 857-863 (2017).

14. Sun, S. Y. et al. Chemical signaling and functional activation in colloidosomebased protocells. Small 12, 1920-1927 (2016).

15. Huang, $X$. et al. Interfacial assembly of protein-polymer nano-conjugates into stimulus-responsive biomimetic protocells. Nat. Commun. 4, 2239 (2013).

16. Huang, X., Patil, A. J., Li, M. \& Mann, S. Design and construction of higherorder structure and function in proteinosome-based protocells. J. Am. Chem. Soc. 136, 9225-9234 (2014).

17. Gobbo, P. et al. Programmed assembly of synthetic protocells into thermoresponsive prototissues. Nat. Mater. 17, 1145-1153 (2018).

18. Joesaar, A. et al. DNA-based communication in populations of synthetic protocells. Nat. Nanotechnol. 14, 369-378 (2019).

19. Kumar, P., Patil, A. J. \& Mann, S. Enzyme-powered motility in buoyant organoclay/DNA protocells. Nat. Chem. 10, 1154-1163 (2018)

20. Koga, S., Williams, D. S., Perriman, A. W. \& Mann, S. Peptide-nucleotide microdroplets as a step towards a membrane-free protocell model. Nat. Chem. 3, 720-724 (2011)

21. Nakashima, K. K., Baaij, J. F. \& Spruijt, E. Reversible generation of coacervate droplets in an enzymatic network. Soft Matter 14, 361-367 (2018). 
22. Kumar, B. et al. Chloroplast-containing coacervate micro-droplets as a step towards photosynthetically active membrane-free protocells. Chem. Commun. 54, 3594-3597 (2018).

23. Lv, K. L., Perriman, A. W. \& Mann, S. Photocatalytic multiphase microdroplet reactors based on complex coacervation. Chem. Commun. 51, 8600-8602 (2015).

24. Aumiller, W. M. \& Keating, C. D. Phosphorylation-mediated RNA/peptide complex coacervation as a model for intracellular liquid organelles. Nat. Chem. 8, 129-137 (2016)

25. Tang, T. Y. D., van Swaay, D., deMello, A., Anderson, J. L. R. \& Mann, S. In vitro gene expression within membrane-free coacervate protocells. Chem. Commun. 51, 11429-11432 (2015).

26. Hansen, M. M. K. et al. Macromolecular crowding creates heterogeneous environments of gene expression in picolitre droplets. Nat. Nanotechnol. 11, 191-197 (2016).

27. Drobot, B. et al. Compartmentalised RNA catalysis in membrane-free coacervate protocells. Nat. Commun. 9, 3643 (2018).

28. Poudyal, R. R. et al. Template-directed RNA polymerization and enhanced ribozyme catalysis inside membraneless compartments formed by coacervates. Nat. Commun. 10, 490 (2019).

29. Mason, A. F., Buddingh, B. C., Williams, D. S. \& van Hest, J. C. M. Hierarchical self-assembly of a copolymer-stabilized coacervate protocell. $J$. Am. Chem. Soc. 139, 17309-17312 (2017).

30. Tang, T. Y. D. et al. Fatty acid membrane assembly on coacervate microdroplets as a step towards a hybrid protocell model. Nat. Chem. 6, 527-533 (2014).

31. Deng, N. N. \& Huck, W. T. S. Microfluidic formation of monodisperse coacervate organelles in liposomes. Angew. Chem. Int. Ed. 56, 9736-9740 (2017).

32. Martin, N. et al. Antagonistic chemical coupling in self-reconfigurable hostguest protocells. Nat. Commun. 9, 3652 (2018).

33. Booth, R., Yan, Qiao, Y., Li, M. \& Mann, S. Spatial positioning and chemical coupling in coacervate-in-proteinosome protocells. Angew. Chem. Int. Ed. 58, 9120-9124 (2019).

34. Qiao, Y., Li, M., Booth, R. \& Mann, S. Predatory behaviour in synthetic protocell communities. Nat. Chem. 9, 110-119 (2017).

35. Liu, J. et al. Light-energy transduction in a prototissue flow reactor. Nat. Mater. just submitted (2019).

36. Tian, L. et al. Nonequilibrium spatiotemporal sensing within acoustically patterned two-dimensional protocell arrays. ACS Cent. Sci. 4, 1551-1558 (2018).

37. Garenne, D. et al. Sequestration of proteins by fatty acid coacervates for their encapsulation within vesicles. Angew. Chem. Int. Ed. 55, 13475-13479 (2016).

38. Williams, D. S., Patil, A. J. \& Mann, S. Spontaneous structuration in coacervate-based protocells by polyoxometalate-mediated membrane assembly. Small 10, 1830-1840 (2014).

39. Sartorel, A., Bonchio, M., Campagna, S. \& Scandola, F. Tetrametallic molecular catalysts for photochemical water oxidation. Chem. Soc. Rev. 42, 2262-2280 (2013).

40. Sartorel, A. et al. Polyoxometalate embedding of a tetraruthenium(IV)-oxocore by template-directed metalation of $[\gamma-\mathrm{SiW} 10 \mathrm{O} 36] 8-$ : a totally inorganic oxygen-evolving catalyst. J. Am. Chem. Soc. 130, 5006-5007 (2008).

41. Toma, F. M. et al. Efficient water oxidation at carbon nanotubepolyoxometalate electrocatalytic interfaces. Nat. Chem. 2, 826-831 (2010).

42. Orlandi, M. et al. Ruthenium polyoxometalate water splitting catalyst: very fast hole scavenging from photogenerated oxidants. Chem. Commun. 46, 3152-3154 (2010).

43. Sartorel, A. et al. Oxygenic polyoxometalates: a new class of molecular propellers. Chem. Commun. 47, 1716-1718 (2011).

44. del Mercato, L. L. et al. Catalytic self-propulsion of supramolecular capsules powered by polyoxometalate cargos. Chem. Eur. J. 20, 10910-10914 (2014).

45. Tian, L. et al. Spontaneous assembly of chemically encoded two-dimensional coacervate droplet arrays by acoustic wave patterning. Nat. Commun. 7, 13068 (2016).

46. Tian, L., Li, M., Patil, A. J., Drinkwater, B. W. \& Mann, S. Artificial morphogen-mediated differentiation in synthetic protocell communities. Nat. Commun. 10, 3321 (2019).

47. Bonchio, M. et al. Hierarchical organization of perylene bisimides and polyoxometalates for photo-assisted water oxidation. Nat. Chem. 11, 146-153 (2019).

48. Weinstock, I. A., Schreiber, R. E. \& Neumann, R. Dioxygen in polyoxometalate mediated reactions. Chem. Rev. 118, 2680-2717 (2018).
49. Wang, S. S. \& Yang, G. Y. Recent advances in polyoxometalate-catalyzed reactions. Chem. Rev. 115, 4893-4962 (2015).

50. Lv, H. J. et al. Polyoxometalate water oxidation catalysts and the production of green fuel. Chem. Soc. Rev. 41, 7572-7589 (2012).

51. Burkett, S. L., Press, A. \& Mann, S. Synthesis, characterization, and reactivity of layered inorganic-organic nanocomposites based on 2:1 trioctahedral phyllosilicates. Chem. Mater. 9, 1071-1073 (1997).

52. Han, J. Y. et al. Polyoxometalate immobilized in MIL-101(Cr) as an efficient catalyst for water oxidation. Appl. Catal. A 521, 83-89 (2016).

53. Caliman, E., Dias, J. A., Dias, S. C. L. \& Prado, A. G. S. Solvent effect on the preparation of H3PW12O40 supported on alumina. Catal. Today 107-08, 816-825 (2005).

54. Morgan, D. J. Resolving ruthenium: XPS studies of common ruthenium materials. Surf. Interfaces Anal. 47, 1072-1079 (2015).

55. Anwar, N. et al. Surface immobilization of a tetra-ruthenium substituted polyoxometalate water oxidation catalyst through the employment of conducting polypyrrole and the layer-by-layer (LBL) technique. ACS Appl. Mater. Interfaces 6, 8022-8031 (2014).

\section{Acknowledgements}

We thank EU Horizon 2020 (Marie Skłodowska-Curie grants No. 701876 and 705165; Advanced Grant Scheme No. 740235), BBSRC/EPSRC (Bristol Synthetic Biology Research Centre, BB/L01386X/1) for financial support and use of a plate reader. We thank the Wolfson Bioimaging Facility (BBSRC grant BB/L014181/1), the Chemical Imaging Facility (EPSRC grant "Atoms to Applications" EP/K035746/1), and the Bristol NanoESCA Facility (EPSRC Strategic Equipment Grant EP/M000605/1 and EP/ K035746/1) for help with physical characterization.

\section{Author contributions}

P.G., L.T., P.K., S.T., M.Cat., A.P., M.Car., M.B. and S.M. conceived the experiments. P.G. and S.T. performed experiments on $\mathrm{Ru}_{4} \mathrm{PCV}$ characterization and catalysis in multicatalytic protocell communities; P.K. and P.G. performed experiments on collective synzyme activity in buoyant protocells, L.T. and P.G. performed experiments on catalysis in individual synzyme protocells; M.Cat. performed the XPS measurements; M.Car. and M.B. provided the Ru4POM. P.G., L.T., P.K., S.T., M.Cat., A.P., M.Car., M.B. and S.M. undertook data analysis, discussed the results, and contributed to drafts of the manuscript; P.G. and S.M. wrote the final manuscript.

\section{Competing interests}

The authors declare no competing interests.

\section{Additional information}

Supplementary information is available for this paper at https://doi.org/10.1038/s41467 019-13759-1.

Correspondence and requests for materials should be addressed to A.J.P., M.B. or S.M.

Peer review information Nature Communications thanks the anonymous reviewers for their contribution to the peer review of this work.

Reprints and permission information is available at http://www.nature.com/reprints

Publisher's note Springer Nature remains neutral with regard to jurisdictional claims in published maps and institutional affiliations.

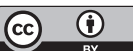

Open Access This article is licensed under a Creative Commons Attribution 4.0 International License, which permits use, sharing, adaptation, distribution and reproduction in any medium or format, as long as you give appropriate credit to the original author(s) and the source, provide a link to the Creative Commons license, and indicate if changes were made. The images or other third party material in this article are included in the article's Creative Commons license, unless indicated otherwise in a credit line to the material. If material is not included in the article's Creative Commons license and your intended use is not permitted by statutory regulation or exceeds the permitted use, you will need to obtain permission directly from the copyright holder. To view a copy of this license, visit http://creativecommons.org/ licenses/by/4.0/.

(C) The Author(s) 2020 